\title{
On the Prediction of the Residual Behaviour of Impacted Composite Curved Panels
}

\author{
Viot Philippe, Ballere Ludovic and Lataillade Jean-Luc \\ Arts et Métiers -ParisTech, Institut de Mécanique et d'Ingénierie, \\ UMR CNRS n 5295, Esplanade des Arts et Métiers, F-33405 Talence
}

France

\section{Introduction}

Composite materials are very often used in the aeronautical industry, because of their high specific strength, they are more appropriate for such applications than metals are. However, one disadvantage of such materials is the problem of detecting damage initiated by impact (e.g., dropping tools, collisions with foreign objects and other accidents), particularly when the reinforcement used is carbon fibre because may not be visible. Therefore, since it is difficult to avoid accidents, it is necessary to evaluate the effects of such damage on the residual resistance of the structure. This approach is related to the concept of the damage tolerance of structures. The structures considered here are filament-wound vessels subjected to high internal pressure loading and damage can be initiated in the carbon-epoxy shell during all their life cycle (manufacturing, storage, etc). In order to qualify the behaviour of these impacted structures, preliminary validation tests have to be done. However, these specific tests are generally very expensive and difficult to perform, especially when the structures' dimensions are large. An alternative way must be developed and a first one is to employ small-scale models.

The use of these reduced scale structures requires the identification of similitude models allowing the extrapolation of the small-scale model behaviour to the real structure. Although largely used in the case of homogeneous materials, such similitude techniques are not significantly developed for composite materials, mainly because of the interactive character of the different and multiscale damage mechanisms. As a first attempt, two scaling rule methods were developed based on a dimensional analysis using Buckingham's Pi theorem (Buckingham, 1914) or defined from dynamic equation of the system (Qian \& Swanson, 1990). From these similitude models, some authors (Morton, 1988, Nettles et al., 1999) studied scale effects on composite structures taking into account the damage evolution during an impact but the gap was important between experimental results and predictions issued from scale models. For our study, in a preliminary phase of this research, scale models were evaluated (Viot et al., 2008) : a first approach consisted to apply similitude laws currently used on two scales (A and B) of composite structures. The purpose of this preliminary study was to predict the behaviour of the composite structure (scale A) from the knowledge of the response of the second scale model (scale B). It has been shown that existing similitude laws can be used to evaluate the elastic response of the two scales of composite structure but these models do not allow simulating the behaviour of the different scales when one of them is damaged; it is due to non linearities. 
For composite structures of large dimensions, an alternative and new approach of smallscale models must be developed since the experimental cost of impact study can be too expensive. Then, the main objective of our work is to predict the residual behaviour of impacted structures when the residual behaviour of small-scale structures is known. And because classical similitude laws cannot be used for damaged composite structures, another approach can be the use of a numerical model coupled with experimental data to predict the residual behaviour of impacted structures.

The proposed method is in three steps and must be applied on small scale panels to predict the behaviour of damaged vessels loaded by internal pressure. Before any numerical simulation, the analysis of the critical damage initiated during an accident must be quantified (point $\mathbf{0}$, figure 1). It is not the accident, the impact which is really important to qualify, even if it is interesting to know the impact conditions (mass, velocity, impactor's geometry, boundaries conditions...), but mostly the different kinds of damages (matrix cracks, fibre breakages or delamination) initiated during this impact which have to be precisely determined. And from the observations and analysis of the impacted composite microstructure, these damages must be classified from their critical effects on the performances of damaged structure. For vessel structures investigated, damages initiated during the impact were mainly delamination between carbon plies and fibre breakage. However, if delamination is a critical phenomenon for composite structures under bending load, this damage has not a drastic effect on vessel residual behaviour because the gap appearing between two delaminated plies decreases when the vessel is under the pressure and the propagation of delamination is then not effective. On the contrary, the breakage of fibres under tensile loading can obviously have a significant effect on the residual performance of the vessels.

From this preliminary study "identification of damage on real structure", the critical kind of damage was quantified and its effect must be experimentally and numerically evaluated on small scale structure. The main objective of the step 1 is then the development and the calibration of a numerical model, able to estimate the response of impacted small-scale structure: first, the critical damage has to be experimentally reproduced on small-scale structure by impact (working package $\mathbf{0}$, figure 1). Secondly, this damage must be controlled and precisely quantified (nature and size) at the scale of the composite microstructure (working package 2 , figure 1). Finally, the residual behaviour of small-scale structure is estimated (working package $\mathbf{3}$, figure 1) by imposing a state of loading close to the one imposed on the real structure (in order to initiate the propagation of the critical damage on small scale model in similar loading conditions than the ones imposed on real structure). This experimental approach is essential to calibrate the numerical model which has to be developed (working package $\mathbf{4}$, figure 1), in taking into account the damage at the scale of the microstructure, in order to estimate the residual response of the small-scale structure.

The second step of this methodology is the evaluation of the performance of the numerical model. The same experimental study "impact - analysis of the damage- identification of the residual performance" is carried out on a second small-scale structure to obtain experimentally the effect of the damage on the residual behaviour of a second composite structure. This effect is also numerically evaluated in using the model developed during step 1. The performance of this model to predict the residual response of damaged composite structure is obtained from the comparison between experimental and numerical results obtained on the second small-scale structure (working package $\mathbf{6}$, figure 1). 


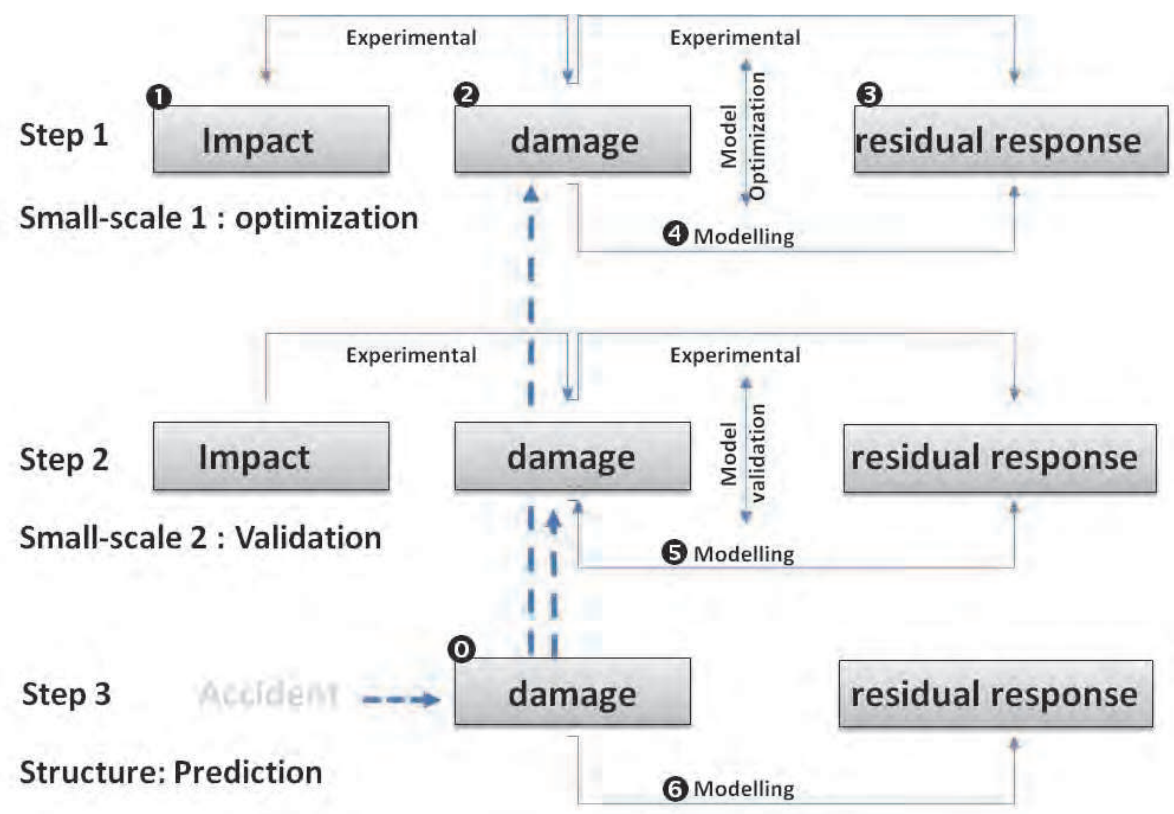

Fig. 1. Scheme of the multi-scale methodology

Finally the third step of the method is the prediction of the residual behaviour of the real structure. The critical damage identified on the real structure at the beginning of this methodology is implemented on the numerical simulation of the real structure. The residual behaviour of this structure can be then numerically estimated (working package $\mathbf{6}$, figure 1 ). This methodology was carried out for the study of the behaviour of impacted carbon-epoxy vessels under pressure. As an experimental study of damage tolerance using this type of structure is very expensive, the experiments were performed on curved panels extracted from tubes which had the same geometrical and mechanical properties as the vessels. The experimental procedure was carried out on these curved panels and the whole of the results were presented in a previous paper (Ballère et al., 2008): Firstly, the specimens were impacted to simulate an accident which can occur on such structures. Then, they were loaded in tension, according to their longitudinal axes, to reproduce the axial stresses caused by internal pressure being applied to the vessels' bottoms. The residual tensile strength was determined according to the initial damage states of the specimens.

The objective of this paper is to present a progressive failure analysis for the prediction of the residual properties of impacted curved specimens loaded in tension. First, the numerical results are compared with the experimental results obtained from undamaged specimens. Then, the damage observed experimentally is implemented numerically and the residual tensile strength is compared to the experimental results.

This methodology uses two scales of specimens. The first - close to the real scale - is used to validate the numerical modelling. The second- half the size of the first - is employed to highlight the mechanisms which have to be taken into account for the high-scale reduction of curved composite structures. 


\section{Numerical simulation}

The modelling proposed in this study is based on a progressive failure analysis at the mesoscale (i.e., at the scale of the layer and the interface). Three steps are needed to build this model: i) choose a failure criterion; ii) choose damage kinetic; and iii) determine the consequences of the criterion activation on the elastic properties of the layer. Many approaches can be found in the literature to describe the progressive failure of a laminate, e.g., a state of the art approach was presented during the World Wide Failure Exercise (Kaddour et al., 2004). Different criteria are used in these approaches: for example, Ambur (Ambur et al., 2004) and Laurin (Laurin et al., 2007) use the Hashin-Rotem multi-criterion (Hashin and Rotem 1973); Bogetti (Bogetti, 2004) a 3-D maximum strain criterion and Zinoviev (Zinoviev, 2002) a maximum stress criterion. For this study, we have chosen the following maximum strain criterion.

\subsection{Criterion: Maximum strain}

The numbering of the orthotropic axes of the layer is shown in Figure 2a. The failure criterion is based on a damage variable, $\mathrm{d}_{\mathrm{ij}}$, defined as

$$
\frac{\varepsilon_{i j}^{n}}{\varepsilon_{i j}^{R}}=d_{i j}^{n}
$$

where $i$ and $\mathrm{j}$ correspond to the orthotropic axes of the layer $(\mathrm{i}, \mathrm{j}=1, \ldots 3), \varepsilon_{i j}^{n}$ is the component $\mathrm{ij}$ of the strain tensor at increment $\mathrm{n}$ and $\varepsilon_{i j}^{R}$ its value to failure. The failure occurs when $d_{i j} \geq 1$. In this formulation, it should be noted that, for $\varepsilon_{i j}<0$ (i.e., in compression), $\mathrm{d}_{\mathrm{ij}}$ is always negative so that there is no failure in compression. This assumption can be justified here since this modelling is applied to the prediction of residual strength in tension. As soon as the failure occurs (i.e., $d_{i j} \geq 1$ ), the elastic modulus, $\mathrm{E}_{\mathrm{ij}}$, is reduced instantaneously to a residual value close to 0 (Figure $2 \mathrm{~b}$ ). This value is maintained regardless of the postfailure loading. This property avoids the healing of the damaged material. This approach proposes a degradation of the elastic properties of the layer in an independent way and the interface is considered non-damaging.

This progressive failure analysis has been implemented in the Finite Element Code, ZéBuLoN.
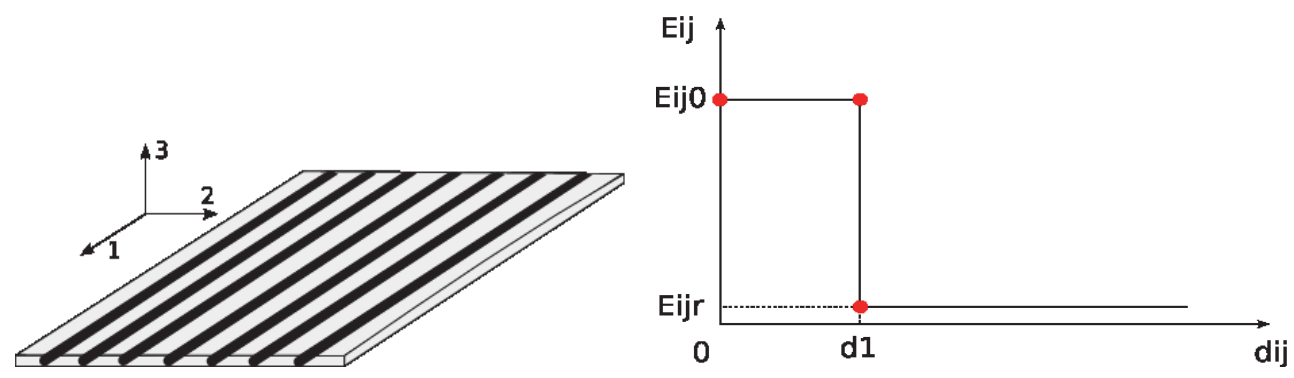

Fig. 2. a (left) Numbering of orthotropic axis, b (right) variation of elastic properties 


\subsection{Numerical simulation of curved panel}

In order to validate this numerical approach, experimental tests were performed on two scales of composite curved panels. The methodology used and the results obtained for one of these scales of specimens (called «specimens Ø600») is presented in (Ballère et al., 2008). The first step in the numerical modelling is to check that the behaviour of an undamaged specimen is well-predicted.

\subsubsection{Undamaged curved panel}

The stacking sequence of the laminate used here is:

$$
\text { Inner- } \left.\left(90^{\circ}\right)_{2} /\left[\left( \pm 20^{\circ}\right)_{2} /\left(90^{\circ}\right)_{2}\right]_{3}\right\} \text {-Outer }
$$

For this modelling, the stacking sequence has been simplified and has been chosen to model the layers oriented at $+20^{\circ}$ and $-20^{\circ}$ independently (see Figures 3 and 4). For this scale of specimens, $\mathrm{n}$ is equal to 1 .

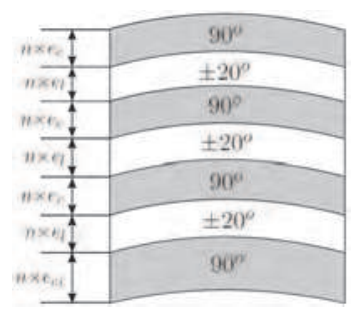

Fig. 3. Stacking sequence of the real structure

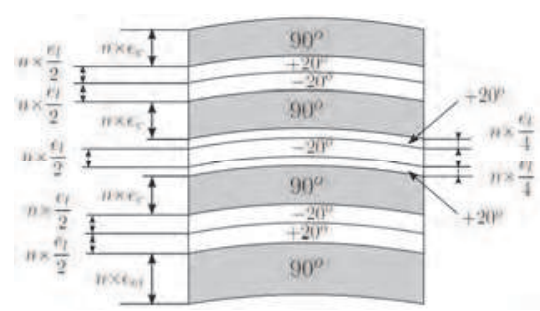

Fig. 4. Stacking sequence of the numerical specimen

The laminate is not symmetrical because the inner circumferential layer is thicker $\left.\left(\mathrm{e}_{\mathrm{c} i}\right\}\right)$ than the others $\left(\mathrm{e}_{\mathrm{c}}\right)$. Nevertheless, the choice of the stacking sequence for the numerical specimen was made in order to try to create a nearly symmetrical laminate according to the mid-plane so that the modelling would be easier. The elastic properties of the carbon/epoxy used are:

\begin{tabular}{|c|c|c|c|c|c|c|}
\hline$E_{1}(G P a)$ & $E_{2}(G P a)$ & $G_{12}(G P a)$ & $v_{12}$ & $v_{21}$ & $\sigma_{1}^{R}(M P a)$ & $\sigma_{2}^{R}(M P a)$ \\
\hline 165 & 7.1 & 3.9 & 0.39 & 0.015 & 2610 & 38 \\
\hline
\end{tabular}

Table 1. Mechanical properties

The dimensions of the panels and the boundary conditions used in this numerical modelling are shown in Figure 5. They correspond to those used to perform the experimental tests. The radius of the curvature is $278 \mathrm{~mm}$.

The influence of the element formulation for the failure prediction of these curve specimens was investigated in a previous study in which it was shown that the through-thickness displacement field is non-linear in tension. Therefore, in this research, an element denoted C3D20 (quadratic brick element) in ZeBuLoN (Carrère et al., 2009) has been chosen to model, through the thickness, each layer of a different orientation making it possible to detect the non-linearity of the displacement field. 


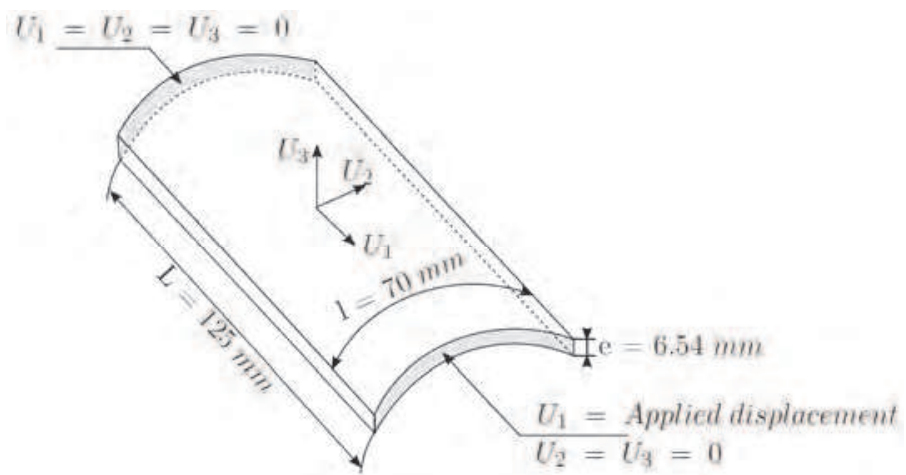

Fig. 5. Geometry and boundary conditions

\subsubsection{Damaged curved panel $\phi 600$}

To implement the damage numerically, the typology of the damage mechanisms generated by impact had to be observed. This observation was undertaken during the experimental study (Ballère et al., 2008) and the results are summarized below.

For the impact tests, the specimen was clamped between two aluminium blocks and tightened with screws. It was fully supported on both surfaces except for a circular region of $30 \mathrm{~mm}$ in diameter in the centre corresponding to the impact zone. With this specimenmounting device, classical damage mechanisms were observed. Delamination initiates and propagates during impact, even at low energy, but the delamination zone is always restricted in the centre because of the specimen-mounting device. Since impact energy is not fully dissipated by delamination, intra-laminar failures also occur (fibre failure, matrix cracking). Impacted specimens were loaded in quasi-static tension in order to evaluate their residual behaviour. It is well-known that the most prejudicial damage mechanism for laminates loaded in tension is fibre failure. For this reason, specific attention was paid to this phenomenon.

Table 2 presents some results of microscopic observations performed on specimens impacted with different impact energy levels. Each row is associated with a specific layer of the laminate. The columns of this table are ranked in order of increasing impact energy. The $m$ symbols indicate layers in which fibre breakages were observed. The number of layers damaged during the impact increased with the increase in the impact energy.

\begin{tabular}{|c|c|c|c|c|c|}
\hline \multicolumn{2}{|c|}{ Structure } & $\begin{array}{c}\text { Damage1 } \\
(\mathrm{E}=22 \mathrm{~J})\end{array}$ & $\begin{array}{c}\text { Damage2 } \\
(\mathrm{E}=30 \mathrm{~J})\end{array}$ & $\begin{array}{c}\text { Damage3 } \\
(\mathrm{E}=38 \mathrm{~J})\end{array}$ & $\begin{array}{c}\text { Damage4 } \\
(\mathrm{E}=71 \mathrm{~J})\end{array}$ \\
\hline $90^{\prime \prime}$ & Circ. 1 & $m$ & $m$ & $m$ & $m$ \\
\hline $\pm 20^{\circ}$ & Long. 1 & $m$ & $m$ & $m$ & $m$ \\
\hline $90^{\circ}$ & Circ. 2 & & $m$ & & $m$ \\
\hline $\pm 20^{a}$ & Long. 2 & & & $m$ & $m$ \\
\hline $90^{\circ}$ & Circ. 3 & & & & $m$ \\
\hline $\pm 20^{\circ}$ & Long. 3 & & & & $m$ \\
\hline $90^{\circ}$ & Circ. 4 & & & & $m$ \\
\hline
\end{tabular}

Table 2. Damage levels experimentally evaluated 
In order to model the damage observed experimentally in a cylinder of $30 \mathrm{~mm}$ in diameter, an equivalent zone of the numerical specimen was defined (Figure 18). One or many layers can be damaged independently in this zone by decreasing all the elastic modulus $E_{i j}$ to their residual value. This assumption can be justified since, at each time a fibre failure was observed in a layer, all the primary damage mechanisms (i.e., matrix cracking, fibre-matrix shear failures) were also observed. It is possible to suspect that the elastic properties of the layer decrease along all directions in the impact zone. In a first approach, the Poisson's ratio is not degraded.

All these observations were used to validate this modelling in the case of impacted specimens.

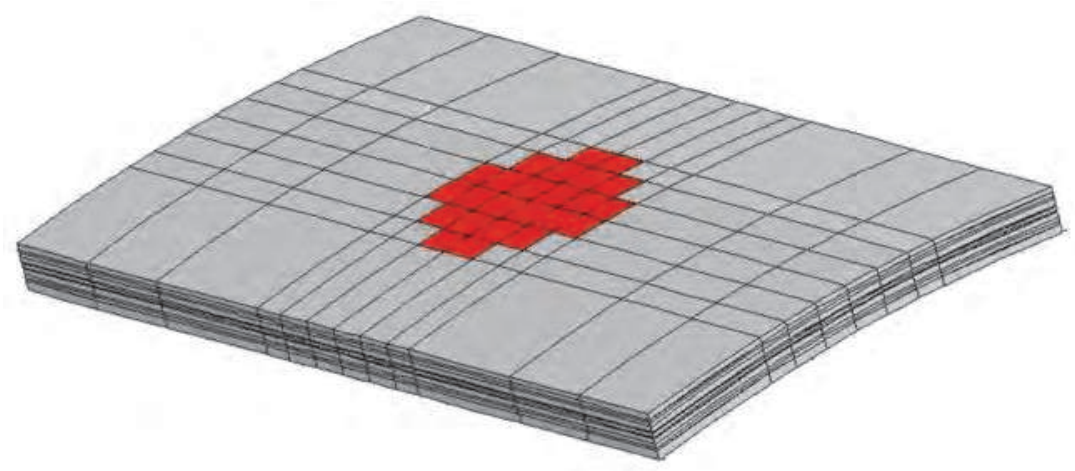

Fig. 6. Damage implementation

\section{Model optimisation on a first small scale structure $\phi 600$}

\subsection{Numerical results on non impacted panels: effect of the mesh size}

Most progressive damage laws are very dependent on the mesh fineness. Therefore, two meshes of different element sizes were first considered in order to evaluate this effect (Figures 7 and 8). Mesh B consists of four times more elements in its surface than does mesh A. There is the same number of elements through the thickness in each mesh.
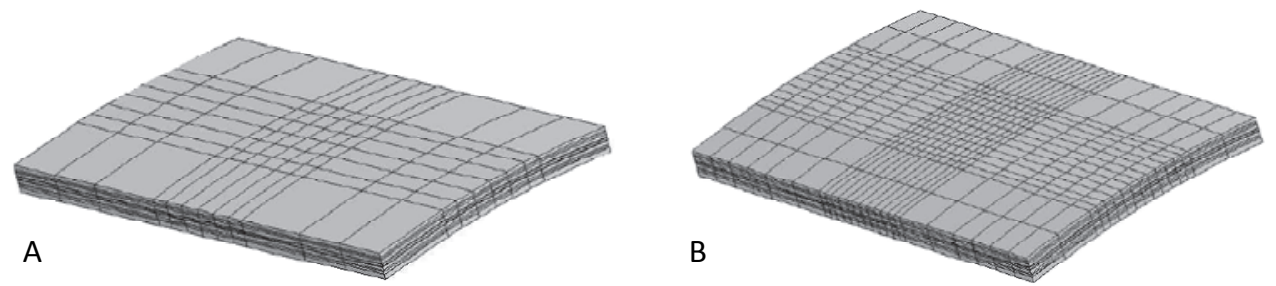

Fig. 7. Mesh A and Mesh B

Figure 8 shows a comparison between the stress-strain curves obtained using these two meshes. The horizontal line corresponds to the mean ultimate stress determined during experimental tests. Obviously, the two curves are similar in the first part of the loading, but 
a plateau occurs for them close to the experimental failure value and then, after this plateau, the main difference appears. For mesh $\mathrm{A}$, the loading increases to reach a final failure value which is very far from the experimental value. Using mesh B, the final failure occurs just after this plateau with a stress value close to the experimental failure $(3 \%)$. The decrease in the element size allows the failure value reached to be close to the experimental results. This can be explained by focusing on a zone of the graph located around the plateau (Figure 8).

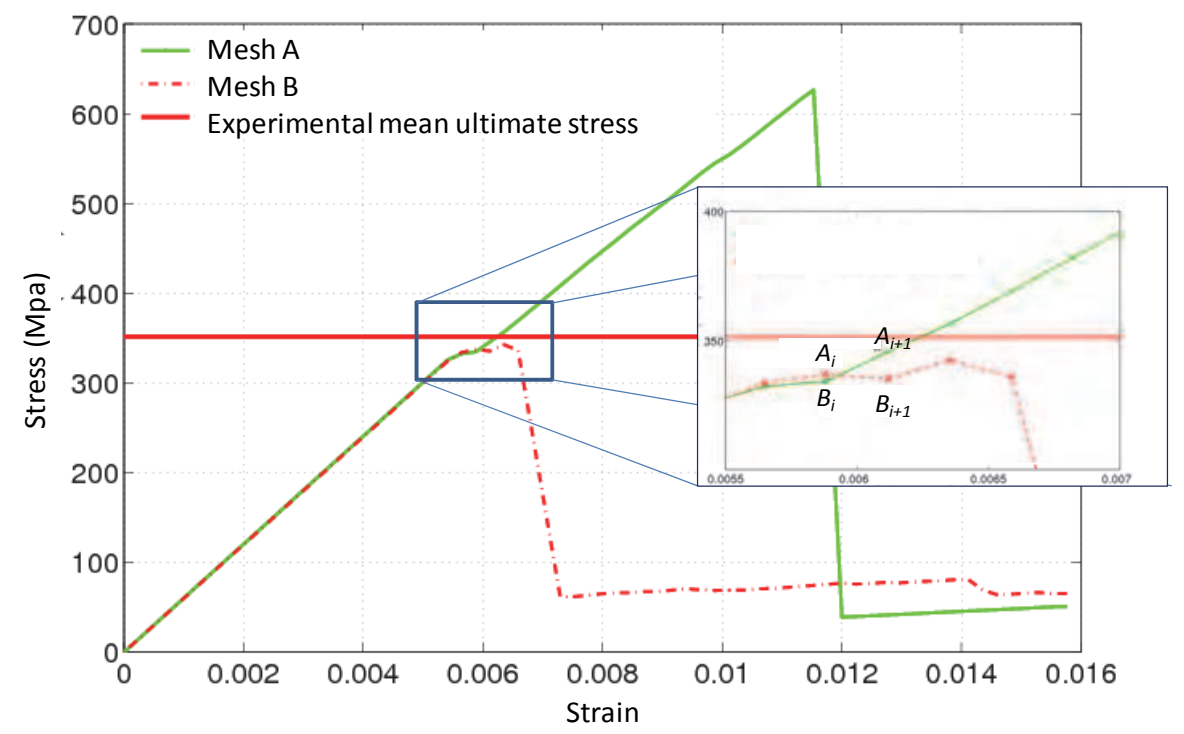

Fig. 8. Influence of the element size on the numerical stress vs. strain response

In order to identify the mechanisms which change according to the mesh fineness, attention has been paid to the criterion activation at particular points: i) points $A_{i}$ and $B_{i}$, located just before the change of behaviour; and ii) points $A_{i+1}$ and $B_{i+1}$, located at the next increment for mesh $A$ and mesh $B$ respectively. At points $A_{i}$ and $B_{i}$, the criterion is highly activated by the damage variable $d_{22}$, (related to the orthoradial strain) in all the circumferential layers. The stress plateau observed for the two meshes is mainly due to this failure mode. For this level of loading, the damage variable, $\mathrm{d}_{33}$, is also equal to 1 in many elements of the circumferential layers. Failures due to transverse shear stresses (damage variables $\mathrm{d}_{13}$ and $\mathrm{d}_{23}$ ) also appear in all the layers of the laminate. The main difference between the behaviour obtained using these two meshes is in the detection of in-plane shear failures. The criterion is activated (i.e., $d_{12}=1$ ) in many elements with mesh B (Figure 9, left) but not in any element of the mesh A. The increase in the mesh fineness allows the detection of in-plane shear failures to be earlier.

This difference between the predictions from these two meshes is amplified at higher loading levels (i.e., points $A_{i+1}$ and $B_{i+1}$ ). The criterion is still not activated with mesh $A$ for in-plane shear stresses whereas there are many in-plane shear failures detected for mesh $B$ in all the layers of the laminate and they are close to the free-edges of the specimen (figure 9, right). Experimentally, these failures lead to the delaminations observed post-mortem. 


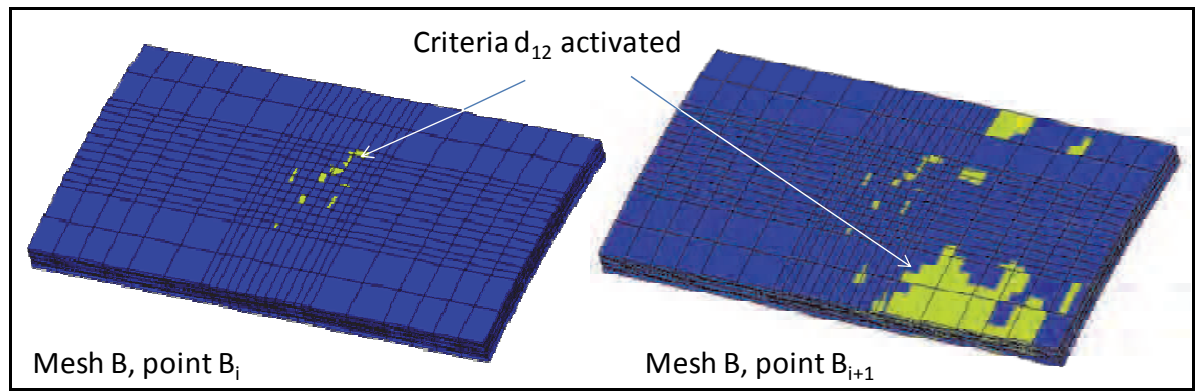

Fig. 9. Damage variable $d_{12}$ calculated with mesh $B$ at the point $B_{i}\left(\right.$ left) and at the point $B_{i+1}$ (right)

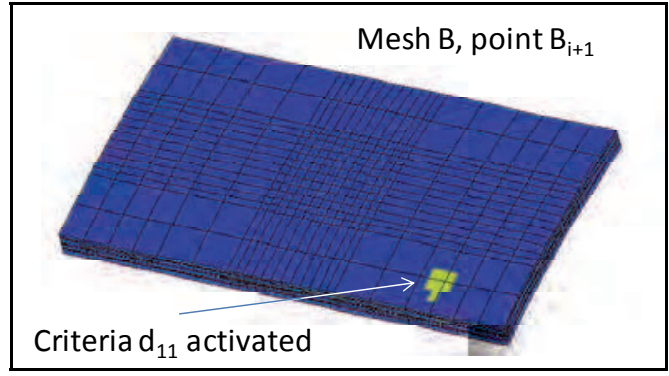

Fig. 10. Damage variable $d_{11}$ calculated with mesh $B$ at the point $B_{i+1}$

The existence of in-plane shear failures exhibited when using mesh B leads to failures in the fibre mode (i.e. damage variable $d_{11}$ ) in the longitudinal layers, as shown in Figure 10. This phenomenon leads to the global failure of the specimen. By decreasing the element size, it was possible to detect earlier the initiation of two damage mechanisms strongly prejudicial to the integrity of the specimens: in-plane shear failures and fibre breakages.

\subsection{Numerical results on impacted panels}

Since the proposed modelling was validated in the case of undamaged specimens, the next step was to use this model to predict the residual behaviour of impacted specimens. Each damage level presented in Table 2 was modelled and the residual tensile behaviour assessed. The stress-strain curves of the pre-damaged specimens are presented in Figure 11 and are compared with the response of the undamaged specimen (in using the mesh A).

Focusing on the slope of the first linear part of these curves, it appears that the more the predamage state is important, the more the slope decreases. This slope can be related to the homogenized elastic modulus of the specimens. Obviously, the damage generates decreasing stiffness. This phenomenon has been observed experimentally (Ballère et al., 2008) and could be analyzed in detail using this approach. Nevertheless, because the aim of this study is to predict the residual tensile strength of impacted specimens, particular attention was paid to the ultimate stress.

For each curve, the ultimate stress was extracted and then plotted versus the associated impact energy (figure 12). Concerning an undamaged specimen, it was shown that an increase in mesh fineness leads to a global failure located at the stress plateau level. Thus, 
for this curve, the ultimate stress chosen was equal to this plateau value. These numerical predictions are in good agreement with the experimental results. Experimentally, there is a bi-linear evolution of the ultimate stress according to the impact energy. The impact energy yields (i.e., damage), when the ultimate stress starts to decrease. For this scale of specimens, this yield energy is equal to $40 \mathrm{~J}$. This phenomenon is also observed in this numerical analysis since the ultimate stress obtained for the «damage 3 » level is more or less the same as that for an undamaged specimen.

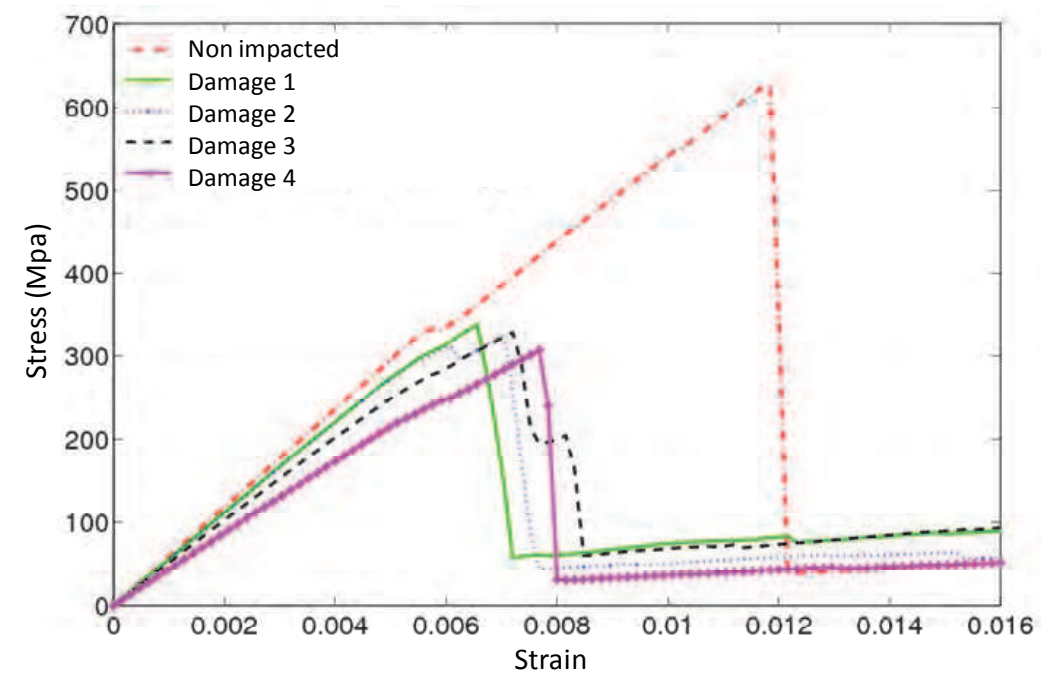

Fig. 11. Numerical stress vs. strain response for impacted specimens

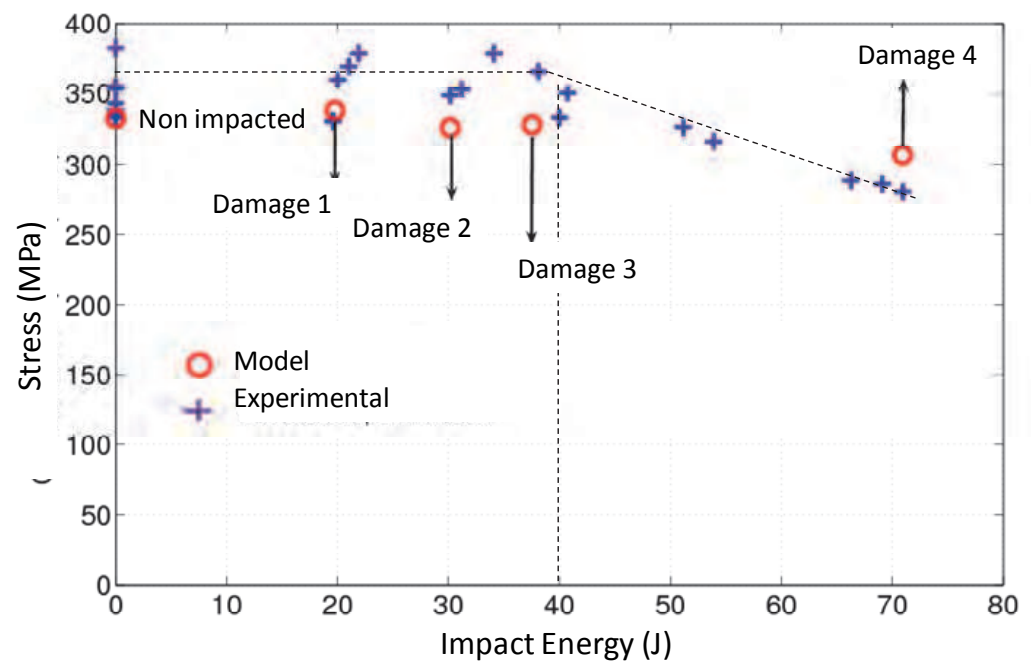

Fig. 12. Comparison between model predictions and experimental results 
It is interesting to note that an increase in the damage state of a specimen does not involve, systematically, a decrease in its ultimate stress. For example, the ultimate stress of a specimen damaged according to the «damage 3» level is almost equal to that of a specimen associated with the «damage 2» level (figure 12). For instance, the «damage 2» level corresponds to the failure of two first circumferential layers (oriented at $90^{\circ}$ ) and one intermediate longitudinal layer ( long. 1 , oriented at $\pm 20^{\circ}$, table 2) while the «damage 4 » level is associated with the failure of the first circumferential layer and the two longitudinal layers (long. 1 and long. 2, table 2). For flat laminates, degradation of the longitudinal fibres is very harmful to the strength of the specimen in tension compared with degradation of the fibres oriented at $90^{\circ}$. It seems that, for these curved specimens, fibres oriented at $90^{\circ}$ play a very significant role in their tensile strengths. Also, the influence of the damage organization through the thickness of the laminate has to be studied.

\subsubsection{Influence of the damage on residual behaviour prediction}

Experimentally, damage assessment was conducted using optical microscopy with a limited number of specimens. From the results, it was possible to correlate a residual tensile strength and an initial damage state of the specimen. Nevertheless, after the dynamic test, a variability of the damage could be suspected due to: i) dispersion of the properties of the different components; ii) variability in the mechanical properties of the specimens introduced by the manufacturing process; and iii) the boundary conditions used for the impact tests possibly being slightly different for each test. This damage variability was reflected in the experimentally observed strength dispersion. However, numerically, it cannot be taken into account without implementing a random damage variable.

In this approach, it was decided to quantify this strength variability by studying different cases of damage. »). Two new damage cases (called "Virtual damage A» and «Virtual damage $\mathrm{B}$, table 3) were modelled to evaluate the residual behaviour of composite specimens if these kinds of degradation are imposed during an impact. The "virtual damage A» level was established from the «Damage 3» by adding the fibre breakage in the second circumferential layer. The « virtual damage $B$ » was a damage level located between the «Damage A» level and the «Damage 4» level where five layers are damaged.

\begin{tabular}{|c|c|c|c|c|c|c|c|}
\hline \multicolumn{2}{|c|}{ Structure } & \multirow{2}{*}{$\frac{\text { Dam.1 }}{m}$} & \multirow{2}{*}{$\frac{\text { Dam. } 2}{m}$} & \multirow{2}{*}{$\frac{\text { Dam. } 3}{m}$} & \multirow{2}{*}{$\begin{array}{c}\text { Virtual } \\
\text { Dam. A } \\
m\end{array}$} & \multirow{2}{*}{$\begin{array}{c}\text { Virtual } \\
\text { Dam. B } \\
m\end{array}$} & \multirow{2}{*}{$\frac{\text { Dam. } 4}{m}$} \\
\hline $90^{\circ}$ & Circ. 1 & & & & & & \\
\hline \multirow{2}{*}{$\frac{ \pm 20^{\circ}}{90^{\circ}}$} & Long. 1 & $m$ & $m$ & $m$ & $m$ & $m$ & $m$ \\
\hline & Circ. 2 & & $m$ & & $m$ & $m$ & $m$ \\
\hline \multirow{2}{*}{$\frac{ \pm 20^{\prime}}{9 \sigma^{\circ}}$} & Long. 2 & & & $m$ & $m$ & $m$ & $m$ \\
\hline & Circ. 3 & & & & & $m$ & $m$ \\
\hline \multirow{2}{*}{$90^{\circ}$} & Long. 3 & & & & & & $m$ \\
\hline & Circ. 4 & & & & & & $m$ \\
\hline
\end{tabular}

Table 4. Add of two damage level cases (A and B) for specimens $\phi 600 \mathrm{~mm}$

An increase in the initial damage state (from «Damage 3» to «Damage «A») obviously leads to a decrease in the ultimate stress $(7 \%)$. This decrease is equal to $16 \%$ when one circumferential layer more than «Damage $A$ » is damaged («Damage $B$ »). For the damage $B$, the residual tensile strength is lower than the ultimate stress calculated for the damage 4 and experimentally obtained in any case of impact energy. 


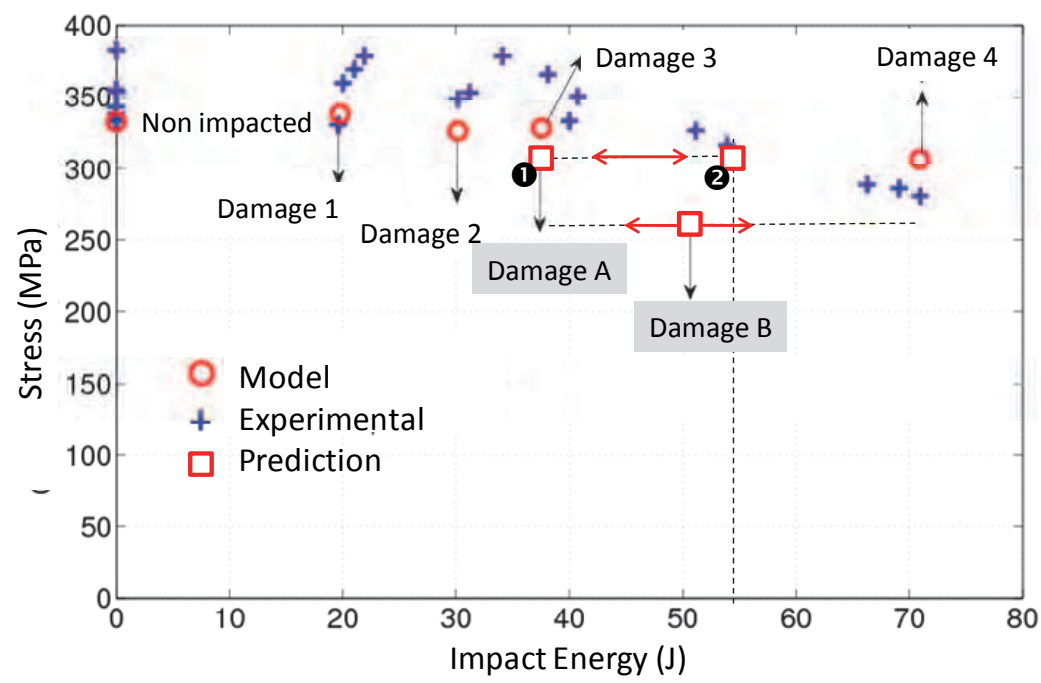

Fig. 12. Comparison between model predictions for two new damages (A and B)

These two new results were plotted on the ultimate stress vs. impact energy diagram. It is clear that we cannot determine the level of impact energy necessary to obtain these two damage states $\mathrm{A}$ and $\mathrm{B}$, we can just consider that the energy levels to reach these damages are in the range of the impact energies of the damage 3 and 4 (if we do not consider any variability of the composite specimen damage to the impact energy). For the damage $\mathrm{A}$, the ultimate stress of which is really close the value numerically computed for the damage 3 , it can be firstly assumed that the effect of supplementary damaged circumferential layers is not significant for the damage A (location-, figure 12). Or, in another way, the impact energy to obtain the damage A can be estimated to $55 \mathrm{~J}$ (location 2, figure 12) by comparing the ultimate stress obtained experimentally to those one derived numerically.

In a first conclusion the used damage model is able to represent the residual resistance of a curved panel under tensile loading. However, it requires an identification of the damage induced during the impact. In the case of specimens Ø600, an increase in the number of damaged layers leads, beyond a specific threshold, to a global decrease in the residual strength. This decrease appears regardless of the type of damaged layers (i.e., circumferential or longitudinal). The shape of this decrease depends slightly on the location of the damaged layers through the thickness of the laminate. With the knowledge of the morphology and the size of the damage in the microstructure, the behaviour of larger specimen or larger structure previously damaged by an impact could be predicted. The second part of the paper presents the limits of this method and the difficulties which can appear if the scale of the specimen induces supplementary phenomena.

\section{Prediction of the behaviour of impacted structures}

The aim of the approach presented here is to predict the residual behaviour of specimens through the knowledge of the mechanical responses of small-scale specimens. In order to reveal the limits of the scale reduction in the case of curved composite structures, this 
approach was used to predict the residual behaviour of specimens which are half the size of specimens "Ø600".

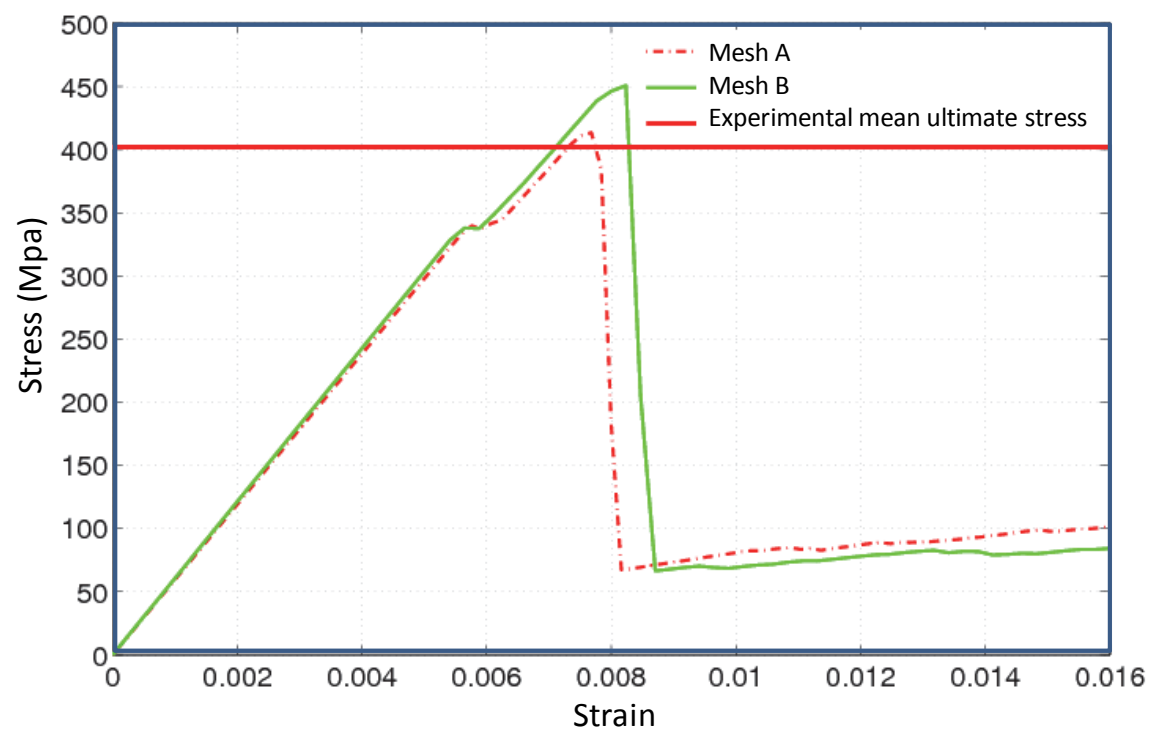

Fig. 13. Influence of the element size on the numerical stress vs. strain response

The dimensions of these small-scale specimens (denoted as specimens" Ø300") were chosen particularly to observe the influence of curvature and thickness on their mechanical responses. The radius of the curvature was divided by two (i.e., $139 \mathrm{~mm}$ ). The thickness was determined by the stacking sequence of the laminate. The "ply-level scaling» technique has been chosen to design the stacking sequence of the small-scale specimens. Thus, the thickness of each layer of a different orientation was divided by two, thereby leading to a global thickness of the laminate equal to $3.27 \mathrm{~mm}$. This technique allows the same stacking sequence to be maintained between each scale while only the layer thickness changes (i.e., in Figures 3 and 4, n=0.5). The width and length are the same for both scales.

The mesh used for this scale of specimens is equivalent to mesh A (Figure 6). Only the element thickness, which is related to the layer thickness, and the radius of the curvature are divided by two.

The influence of the mesh fineness was quantified using four more elements (equivalent to mesh B (Figure 7) for specimens “Ø600"). The stress-strain curves obtained using these two meshes are presented in Figure 13. For this scale of specimens, it seems that the numerical results are less dependent on the element size. A plateau appears in these two curves which, for the same reasons as mentioned in the case of specimens "Ø600", should be related to the global failure of the specimens. For specimens "Ø300", the damage mechanisms responsible for this plateau and, therefore, for the global failure, appear for the same stress value. In order to reduce computation times, mesh A was used for the modelling of the impacted specimens.

These small-scale specimens were tested experimentally and some of the results are presented in the next sub-section. 


\subsection{Numerical results on impacted panels $\phi \mathbf{3 0 0}$}

The different levels of damage modelled for this scale of specimens are presented in Table 5. They correspond to the damages observed experimentally.

\begin{tabular}{|c|c|c|c|c|c|}
\hline \multicolumn{2}{|c|}{ Structure } & $\begin{array}{c}\text { Damage1 } \\
(\mathrm{E}=7 \mathrm{~J})\end{array}$ & $\begin{array}{l}\text { Damage2 } \\
(\mathrm{E}=12 \mathrm{~J})\end{array}$ & $\begin{array}{c}\text { Damage3 } \\
(\mathrm{E}=14.5 \mathrm{~J})\end{array}$ & $\begin{array}{l}\text { Damage4 } \\
(\mathrm{E}=24 \mathrm{~J})\end{array}$ \\
\hline $90^{4}$ & Circ. 1 & $m$ & $m$ & $m$ & $m$ \\
\hline $\pm 20^{\circ}$ & Long. 1 & & $m$ & $m$ & $m$ \\
\hline $90^{\circ}$ & Circ. 2 & $m$ & $m$ & $m$ & $m$ \\
\hline $\pm 20^{\circ}$ & Long. 2 & & $m$ & $m$ & $m$ \\
\hline $90^{\circ}$ & Circ. 3 & & $m$ & & $m$ \\
\hline $\pm 20^{\circ}$ & Long. 3 & & & $m$ & $m$ \\
\hline $90^{\circ}$ & Circ. 4 & & & & $m$ \\
\hline
\end{tabular}

Table 5. Damage levels experimentally evaluated

Experimentally, a significant dispersion of the ultimate stress of the undamaged specimens is observed (figure 14). This dispersion decreases as soon as the specimens are pre-damaged by impact. Indeed, the defect initiated by the dynamic test restricts and governs the possible locations of failure initiation. Considering only one point, located at the mean ultimate stress for the undamaged specimens, it seems that there is a yield damage point from which the tensile strength starts to decrease.

The numerical predictions are in good agreement with the experimental results for the mostdamaged specimens (i.e., «damage 4» level). They are located in the same area as the experimental dispersions for the undamaged specimens. Between these two damage levels, the numerical results do not match with those of the experiments. Moreover, the bi-linear evolution of the ultimate stress according to the impact energy cannot be predicted by this modelling.

It has been shown that this progressive failure analysis allows the residual tensile strength of one scale of curved specimens to be predicted. Unfortunately, it cannot be used for the prediction of the residual behaviour for smaller scale of specimens.

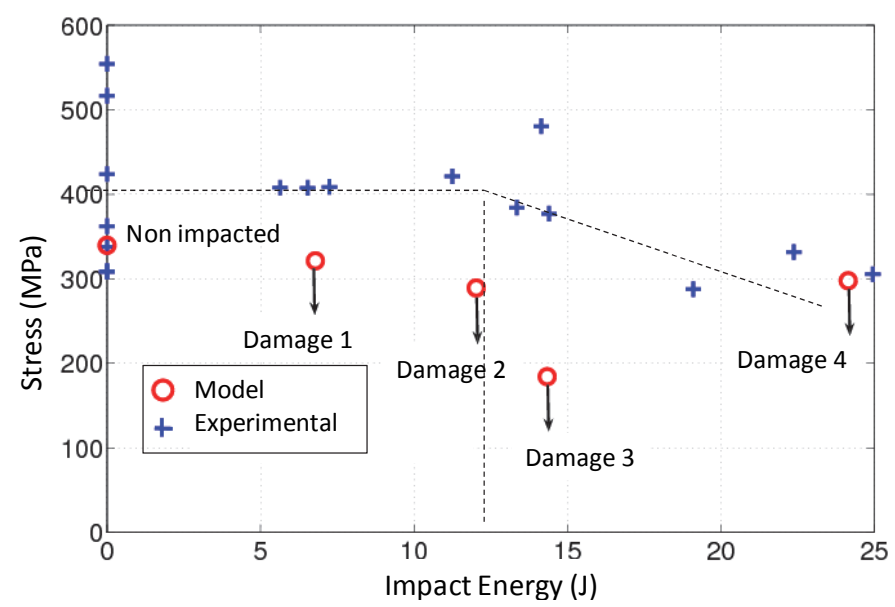

Fig. 14. Comparison between model predictions and experimental results 
Because the numerical results are very different from the experimental ones in the case of small-scale specimens, a complementary study on the influence of the implemented damage on the ultimate stress was carried out. The results of this study are presented in the next section.

\subsubsection{Influence of the damage on residual behaviour prediction}

It was decided to quantify this strength variability by studying different cases of damage. This methodology was used for both scales of specimens starting with specimens "Ø300".

\begin{tabular}{|c|c|c|c|c|c|c|c|}
\hline \multicolumn{2}{|l|}{ Structure } & \multirow{2}{*}{$\begin{array}{l}\text { Dam.1 } \\
\text { m }\end{array}$} & \multirow{2}{*}{$\begin{array}{l}\text { Virtual } \\
\text { Dam. A } \\
\text { m }\end{array}$} & \multirow{2}{*}{$\begin{array}{l}\text { Dam. } 2 \\
m \\
m\end{array}$} & \multirow{2}{*}{$\begin{array}{l}\text { Dam. } 3 \\
m \\
m\end{array}$} & \multirow{2}{*}{$\begin{array}{l}\text { Virtual } \\
\text { Dam. B } \\
\text { m }\end{array}$} & \multirow{2}{*}{$\begin{array}{l}\text { Dam. } 4 \\
m\end{array}$} \\
\hline $90^{\circ}$ & Circ. 1 & & & & & & \\
\hline $\pm 20^{\circ}$ & Long. 1 & & $m$ & $m$ & $m$ & $m$ & $m$ \\
\hline $90^{\circ}$ & Circ. 2 & $m$ & $m$ & $m$ & $m$ & $m$ & $m$ \\
\hline $\pm 20^{\circ}$ & Long. 2 & & & $m$ & $m$ & $m$ & $m$ \\
\hline$\frac{900}{-90^{4}}$ & Circ. 3 & & & $m$ & & $m$ & $m$ \\
\hline $99^{\prime \prime}$ & Long. 3 & & & & $m$ & $m$ & $m$ \\
\hline & Circ. 4 & & & & & & $m$ \\
\hline
\end{tabular}

Table 4. Add of two damage level cases (A and B) for specimens $\phi 300 \mathrm{~mm}$

Thus, the «Damage A» level was created from the «Damage 1» level by adding the degradation of the first longitudinal layer (see Table 6). The «Damage B» level was established from the "Damage 3» level by adding the degradation of the third circumferential layer. These damage cases were chosen specifically to quantify the influence of one more failed layer on the ultimate stress of a specimen.

Figure 15 shows the ultimate stress evolution according to the impact energy (i.e., the initial damage state) from experimental and numerical analyses.

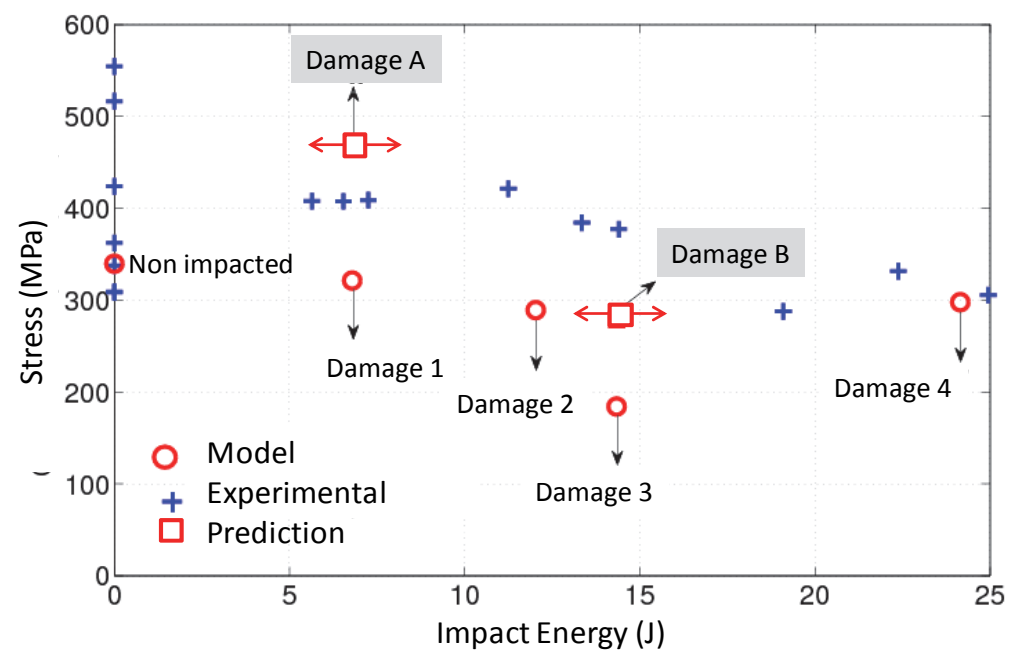

Fig. 15. Comparison between model predictions for two new damages (A and B) 
The ultimate stress obtained in the case of «Damage A» is $46 \%$ higher than in the case of «Damage 1» while the damage level is more important. In the former case, the ultimate stress is also higher than that of the undamaged specimens. It seems that the degradation of all the layers located in the convex part of the curved specimen (i.e., above the mid-plane) increases the residual tensile strength. This is not true in the case of a partial degradation where only the circumferential layers are failed.

Moreover, increasing strength appears in the case of «Damage B». The ultimate stress is $60 \%$ higher than that obtained in «Damage 3» while «Damage B» considers one more circumferential layer failed. All these observations lead to a conclusion regarding the high sensitivity of the ultimate stress according to the damage organization through the thickness of these small-scale specimens $\phi 300$.

It seems that any changes in the radius of the curvature and/or the thickness of the damaged specimens modify the phenomena which occur when they are stressed in tension.

Experimentally, during the tensile test, due to the lay-up and the boundary conditions, the specimen curvature tends to increase between the jaws [Ballère et al., 2008]. Circumferential layers are then progressively damaged according to the inter-fibre mode, thereby causing a change in the orientation of the fibres oriented at $\pm 20^{\circ}$ towards the loading direction $\left(0^{\circ}\right)$. This phenomenon is accentuated by the initial curvature of the specimen. In the case of a partial pre-damage, the type of layers damaged (circumferential or longitudinal), as well as their locations through the thickness of the specimen's boundary conditions, cause this change of orientation.

This phenomenon only exists because the interface between two layers of different orientations can be damaged. Looking at the delaminations observed after the global failure of specimens, the interface integrity strongly influences the residual tensile strength of curved panels. Because damage of the interface is not considered in this model, there are high variations in the ultimate stress in the case of specimens $\varnothing 300$.

\section{Conclusion}

A progressive failure analysis, based on a maximum strain criterion, is presented in this paper. The aim of this approach is to predict the residual tensile behaviour of impacted curved panels. Applied on a scale of specimens (Ø600), it governs the progressive damage which appears at the layer level and leads to a residual tensile strength close to the experimental results. Using this approach, a scenario of failure was proposed and it was shown that the integrity of the circumferential layers (oriented at $90^{\circ}$ ) is very important for ensuring the tensile strength of the curved panels. Indeed, their failure leads to a change of a specimen's curvature between the jaws. This phenomenon alters the orientation of fibres oriented at $\pm 20^{\circ}$ towards the loading direction. High shear stresses then appear and lead to the global failure of the specimen.

This approach has been used for the prediction of the residual tensile strength of a second scale of specimens (Ø300), thinner and more curved than the previous ones. The numerical results are in good agreement with the experimental results in the cases of undamaged specimens and specimens fully damaged in the impact zone (i.e., all the layers are failed). But, for partially damaged specimens, the results do not match those of the experiments. Because of the higher curvatures of the specimens, the residual tensile strength seems to be very dependent on the organization of the damage through the specimen thickness.

This study indicates the need to pay attention to phenomena which can appear during a scale reduction in the case of composite curved structures. A significant decrease in the scale 
of the specimens (i.e., a reduction in the thickness and the radius of the curvature) can change the nature of the main damage mechanisms responsible for the global failure of preimpacted specimens. For slightly curved specimens, it has been shown that the damage which occurs at the interface has to be taken into account to accurately predict the residual tensile strength of pre-impacted specimens.

This possible degradation of interfaces could be conducted using cohesive elements (Elder et al., 2004, Pinho et al., 2006). These elements are implemented between two volumic elements representing two layers of different orientations. Their thickness is equal to 0 before loading. Choosing an appropriate behaviour law, they govern the displacement between two opposite nodes.

First results were obtained by taking into account the degradation of the interfaces. They show that the behaviour is different as soon as the interface is damaged. The change of the curvature, initiated by the failure of the circumferential layers, leads to high stresses which progressively damage the interface. The load transfer cannot take place anymore. This leads to criterion activation according to the fibre-mode in the longitudinal layers and the global failure of the specimen happens. These results confirm the fact that the interface damage has to be considered in order to reflect the physical mechanisms which lead to the failure of curved panels loaded in tension. Nevertheless, the computation time is very important when the cohesive elements are used with an intra-laminar progressive failure analysis. An alternative way has to be found to decrease this high computation time while maintaining the combined modelling of intra-laminar and inter-laminar damage mechanisms.

\section{References}

Ambur, D. R.; Jaunky, N.; Hilburger, M. \& Dávila, C. G. Progressive failure analyses of compression-loaded composite curved panels with and without cutouts Composite Structures, 2004, 65, 143 - 155

Ballère, L.; Viot, P.; Lataillade, J.-L.; Guillaumat, L. \& Cloutet, S. Damage tolerance of impacted curved panels International Journal of Impact Engineering, 2009, 36, 243 - 253

Bogetti, T. A.; Hoppel, C. P.; Harik, V. M.; Newill, J. F. \& Burns, B. P. Hinton, M.; Kaddour, A. \& Soden, P. (Eds.) Predicting the nonlinear response and progressive failure of composite laminates Failure Criteria in Fibre-ReinforcedPolymer Composites, Elsevier, 2004, 402 - 428

Buckingham, E. On physically similar systems; illustration of the use of dimensional equations. Phys.Review, Vol. 4, 1914

Carrere, N.; Rollet, Y.; Leroy, F.-H. \& Maire, J.-F. Efficient structural computations with parameters uncertainty for composite applications, Composites Science and Technology, 2009, 69, 1328 - 1333

Elder, D. J.; Thomson, R. S.; Nguyen, M. Q. \& Scott, M. L. Review of delamination predictive methods for low speed impact of composite laminates Composite Structures, 2004, $66,677-683$

Hashin, Z. and Rotem, A. A fatigue failure criterion for fibre reinforced materials. Journal of Composite Materials, 7:448-464, 1973.

Kaddour, A. S.; Hinton, M. J. \&a. S. P. D. A comparison of the predictive capabilities of current failure theories for composite laminates: additional contributions Composites Science and Technology, 2004, 64, 449 - 476 
Laurin, F.; Carrère, N. \& Maire, J.-F. A multiscale progressive failure approach for composite laminates based on thermodynamical viscoelastic and damage models Composites Part A: Applied Science and Manufacturing, 2007, 38, 198 - 209

Pinho, S.; Iannucci, L. \& Robinson, P. Formulation and implementation of decohesion elements in an explicit finite element code Composites Part A: Applied Science and Manufacturing, 2006, 37, 778 - 789

Qian, Y. \& Swanson S.R. An experimental study of scaling rules for impact damage in fibre composites. J. of Composite Materials, 24:559-570, May 1990.

Viot, P. ; Ballère, L.; Guillaumat, L. \& Lataillade., J.L. Scale effects on the response of composite structures under impact loading. Engineering Fracture Mechanics Journal, Vol 75/9 pp 2725-2736, 2008

Zinoviev, P. A.; Lebedeva, O. V. \& Tairova, L. P. A coupled analysis of experimental and theoretical results on the deformation and failure of composite laminates under a state of plane stress. Composites Science and Technology, 2002, 62, 1711 - 1723 


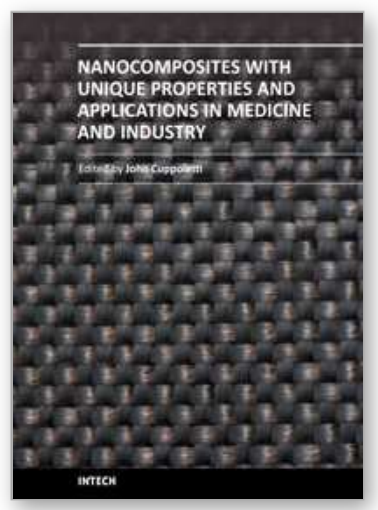

\section{Nanocomposites with Unique Properties and Applications in Medicine and Industry}

Edited by Dr. John Cuppoletti

ISBN 978-953-307-351-4

Hard cover, 360 pages

Publisher InTech

Published online 23, August, 2011

Published in print edition August, 2011

This book contains chapters on nanocomposites for engineering hard materials for high performance aircraft, rocket and automobile use, using laser pulses to form metal coatings on glass and quartz, and also tungsten carbide-cobalt nanoparticles using high voltage discharges. A major section of this book is largely devoted to chapters outlining and applying analytic methods needed for studies of nanocomposites. As such, this book will serve as good resource for such analytic methods.

\section{How to reference}

In order to correctly reference this scholarly work, feel free to copy and paste the following:

Viot Philippe, Ballere Ludovic and Lataillade Jean-Luc (2011). On the Prediction of the Residual Behaviour of Impacted Composite Curved Panels, Nanocomposites with Unique Properties and Applications in Medicine and Industry, Dr. John Cuppoletti (Ed.), ISBN: 978-953-307-351-4, InTech, Available from:

http://www.intechopen.com/books/nanocomposites-with-unique-properties-and-applications-in-medicine-andindustry/on-the-prediction-of-the-residual-behaviour-of-impacted-composite-curved-panels

\section{INTECH}

open science | open minds

\section{InTech Europe}

University Campus STeP Ri

Slavka Krautzeka 83/A

51000 Rijeka, Croatia

Phone: +385 (51) 770447

Fax: +385 (51) 686166

www.intechopen.com

\section{InTech China}

Unit 405, Office Block, Hotel Equatorial Shanghai

No.65, Yan An Road (West), Shanghai, 200040, China

中国上海市延安西路65号上海国际贵都大饭店办公楼 405 单元

Phone: +86-21-62489820

Fax: +86-21-62489821 
(C) 2011 The Author(s). Licensee IntechOpen. This chapter is distributed under the terms of the Creative Commons Attribution-NonCommercialShareAlike-3.0 License, which permits use, distribution and reproduction for non-commercial purposes, provided the original is properly cited and derivative works building on this content are distributed under the same license. 